\title{
Sample size estimation for randomised controlled trials with repeated assessment of patient-reported outcomes: what correlation between baseline and follow-up outcomes should we assume?
}

\author{
Stephen J. Walters ${ }^{*}$ iD, Richard M. Jacques, Inês Bonacho dos Anjos Henriques-Cadby, Jane Candlish,
} Nikki Totton and Mica Teo Shu Xian

\begin{abstract}
Background: Patient-reported outcome measures (PROMs) are now frequently used in randomised controlled trials (RCTs) as primary endpoints. RCTs are longitudinal, and many have a baseline (PRE) assessment of the outcome and one or more post-randomisation assessments of outcome (POST). With such pre-test post-test RCT designs there are several ways of estimating the sample size and analysing the outcome data: analysis of post-randomisation treatment means (POST); analysis of mean changes from pre- to post-randomisation (CHANGE); analysis of covariance (ANCOVA).

Sample size estimation using the CHANGE and ANCOVA methods requires specification of the correlation between the baseline and follow-up measurements. Other parameters in the sample size estimation method being unchanged, an assumed correlation of 0.70 (between baseline and follow-up outcomes) means that we can halve the required sample size at the study design stage if we used an ANCOVA method compared to a comparison of POST treatment means method. So what correlation (between baseline and follow-up outcomes) should be assumed and used in the sample size calculation? The aim of this paper is to estimate the correlations between baseline and follow-up PROMs in RCTs.
\end{abstract}

Methods: The Pearson correlation coefficients between the baseline and repeated PROM assessments from 20 RCTs (with 7173 participants at baseline) were calculated and summarised.

Results: The 20 reviewed RCTs had sample sizes, at baseline, ranging from 49 to 2659 participants. The time points for the post-randomisation follow-up assessments ranged from 7 days to 24 months; 464 correlations, between baseline and follow-up, were estimated; the mean correlation was 0.50 (median 0.51; standard deviation 0.15; range -0.13 to 0.91 ).

Conclusions: There is a general consistency in the correlations between the repeated PROMs, with the majority being in the range of 0.4 to 0.6 . The implications are that we can reduce the sample size in an RCT by $25 \%$ if we use an ANCOVA model, with a correlation of 0.50 , for the design and analysis. There is a decline in correlation amongst more distant pairs of time points.

Keywords: Sample size estimation, Review, Randomised controlled trials, Health Technology Assessment, Publicly funded, Correlations, ANCOVA, Patient-reported outcome measures

* Correspondence: s.j.walters@sheffield.ac.uk

School of Health and Related Research (SCHARR), University of Sheffield, 30

Regent Street, Sheffield S1 4DA, UK

(c) The Author(s). 2019 Open Access This article is distributed under the terms of the Creative Commons Attribution 4.0 International License (http://creativecommons.org/licenses/by/4.0/), which permits unrestricted use, distribution, and reproduction in any medium, provided you give appropriate credit to the original author(s) and the source, provide a link to the Creative Commons license, and indicate if changes were made. The Creative Commons Public Domain Dedication waiver (http://creativecommons.org/publicdomain/zero/1.0/) applies to the data made available in this article, unless otherwise stated. 


\section{Background}

Patient-reported outcome measures (PROMs) are now frequently used in randomised controlled trials (RCTs) as primary endpoints. All RCTs are longitudinal, and many have a baseline, or pre-randomisation (PRE) assessment of the outcome, and one or more postrandomisation assessments of outcome (POST).

For such pre-test post-test RCT designs, using a continuous primary outcome, the sample size estimation and the analysis of the outcome can be done using one of the following methods:

1. Analysis of post-randomisation treatment means (POST)

2. Analysis of mean changes from pre- to postrandomisation (CHANGE)

3. Analysis of covariance (ANCOVA).

For brevity (and following Frison and Pocock's nomenclature [1]), these methods will be referred to as POST, CHANGE and ANCOVA respectively.

Sample size calculations are now mandatory for many research protocols and are required to justify the size of clinical trials in papers before they will be accepted for publication by journals [2]. Thus, when an investigator is designing a study to compare the outcomes of an intervention, an essential step is the calculation of sample sizes that will allow a reasonable chance (power) of detecting a pre-determined difference (effect size) in the outcome variable, when the intervention is actually effective, at a given level of significance. Sample size is critically dependent on the type of summary measure, the proposed effect size and the method of calculating the test statistic [3]. For example, for a given power and significance level, the sample size is inversely proportional to the square of the effect size, so halving the effect size will quadruple the sample size. For simplicity, this paper will assume that we are interested in comparing the effectiveness (or superiority) of a new treatment compared to a standard treatment, at a single point in time post-randomisation.

\section{Sample size}

In a two-group study with a Normally distributed outcome, comparing POST-randomisation mean outcomes between two groups, the number of subjects per group $n_{\text {POST }}$ assuming equal sample sizes and equal standard deviations (SDs) per group for a two-sided significance level $\alpha$ and power $1-\beta$ is [4]:

$$
n_{P O S T} \text { per group }=\frac{2 \sigma^{2}\left[Z_{1-\alpha / 2}+Z_{1-\beta}\right]^{2}}{\delta^{2}},
$$

where: $\delta$ is the target or anticipated difference in mean outcomes between the two groups

$\sigma$ is the SD of the outcome post-randomisation (which is assumed to be the same in both groups)

$Z_{1-\alpha / 2}$ and $Z_{1-\beta}$ are the appropriate values from the standard normal distribution for the $100(1-\alpha / 2)$ and $100(1-\beta)$ percentiles respectively.

Consider a two-group study with a Normally distributed outcome, with a single baseline and single postrandomisation assessment of outcomes. Comparing mean outcomes between two groups, adjusted for the baseline or pre-randomisation value of the outcome, using an ANCOVA model for the number of subjects per group $n_{\text {ANCOVA }}$ (assuming equal sample sizes and equal SDs, at baseline and post-randomisation, per group) for a two-sided significance level $\alpha$ and power 1 $-\beta$ is:

$$
n_{A N C O V A} \text { per group }=\frac{2 \sigma^{2}\left[Z_{1-\alpha / 2}+Z_{1-\beta}\right]^{2}}{\delta^{2}}\left\{1-\rho^{2}\right\} .
$$

Here, $\rho$ denotes the correlation between the baseline and post-randomisation outcomes and $\sigma$ is the postrandomisation $\mathrm{SD}$, which is assumed to be the same as the baseline SD [1,5]. Machin et al. [5] refer to the (1 $\rho^{2}$ ) term as the 'design effect' (DE).

In a two-group study with a Normally distributed outcome, comparing the mean change in outcomes (i.e. post-randomisation outcome - baseline) between two groups, the number of subjects per group $n_{\mathrm{CHANGE}}$ (assuming equal sample sizes and equal SDs, at baseline and post-randomisation, per group) for a two-sided significance level $\alpha$ and power $1-\beta$ is:

$$
n_{\text {CHANGE }} \text { per group }=\frac{2 \sigma^{2}\left[Z_{1-\alpha / 2}+Z_{1-\beta}\right]^{2}}{\delta_{c}^{2}}\{2-2 \rho\} \text {. }
$$

Here, $\delta_{\mathrm{c}}$ is the target or anticipated difference in mean change in outcomes between the two groups and $\sigma$ is the post-randomisation $\mathrm{SD}$ that is assumed to be the same as the baseline SD. If the expected mean values of the baseline outcomes are the same in both groups, which is likely in an RCT, then $\delta c$ is the same as $\delta$.

Figure 1 shows the relationship between the total sample size and the correlation between the baseline and post-randomisation outcomes, for the three methods of sample size estimation (POST, CHANGE and ANCOVA) with a 5\% two-sided significance level, 90\% power, a target difference (a difference in post-treatment means or a difference in mean changes) of 0.50 and an $\mathrm{SD}$ of 1.0. Figure 1 shows how the total sample size is constant for POST irrespective of the baseline and postrandomisation follow-up correlation; the sample size declines as the correlation increases for ANCOVA and 


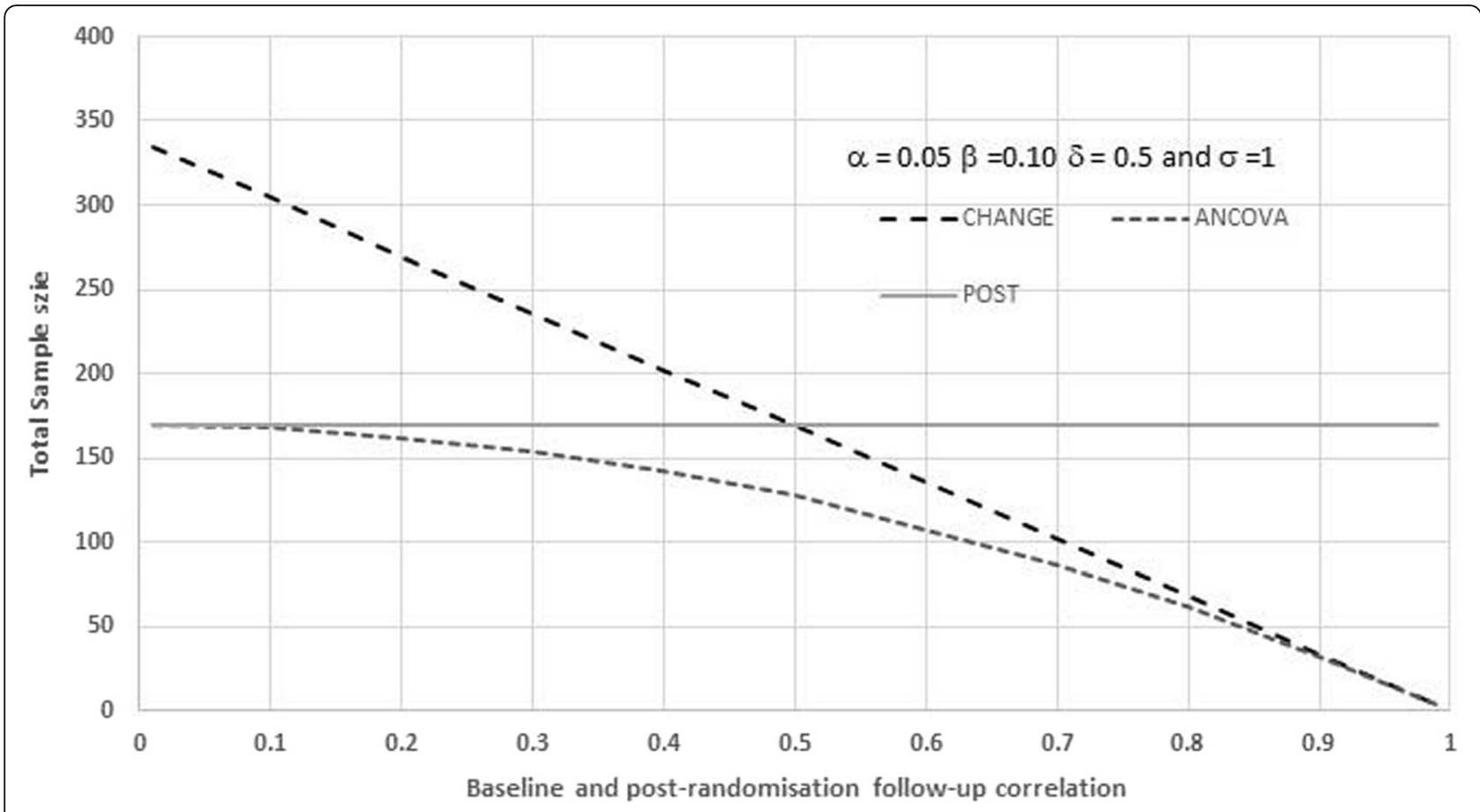

Fig. 1 Relationship between the total sample size and the correlation between the baseline and post-randomisation outcomes for the three methods of sample size estimation (POST, CHANGE and ANCOVA)

CHANGE; and that for correlations above 0.5 the sample size for ANCOVA is always the lowest and is less than or equal to the sample size for CHANGE.

\section{Example}

The SELF study [6] was a multicentre, pragmatic, unblinded, parallel-group randomised control superiority trial designed to evaluate the clinical effectiveness of a self-managed single exercise programme versus usual physiotherapy treatment for rotator cuff tendinopathy (pain or weakness in the shoulder muscles). The intervention was a programme of self-managed exercise prescribed by a physiotherapist in relation to the most symptomatic shoulder movement. The control group received usual physiotherapy treatment. The primary outcome measure was the total score on the Shoulder Pain and Disability Index (SPADI) at 3 months postrandomisation. The SPADI Shoulder Score ranges from 0 , being the best outcome (less disability), to 100 the worst (greater disability).

The original sample size calculation for the SELF trial assumed that a 10-point difference in the mean 3 months post-randomisation SPADI scores between the intervention and control groups would be regarded as a minimum clinical important difference (MCID). It assumed an SD of 24 points, a power of $80 \%$ and a (twosided) significance level of $5 \%$, meaning that using the POST sample size formula, 91 participants per group were required (182 in total). However, in light of new information from an external pilot study, the investigators undertook a sample size re-estimation (SSR) calculation, which was approved by the ethics committee. The new information related to a narrower estimate of population variance from an external pilot RCT $(n=24)$ of 16.8 points on the SPADI and, additionally, a correlation between baseline and 3 months SPADI scores of 0.5. Using the ANCOVA sample size formula, with an SD of 17 points; correlation between baseline and 3 months SPADI scores of $0.50,80 \%$ power, $5 \%$ two-sided significance and a MCID (as before) of 10 points, it was estimated that 34 participants per group were required (68 in total). This contrasts with a sample size of 45 per group using the POST means formula with the revised SD of 17 points. Thus, with a correlation of 0.50 between baseline and follow-up, using the ANCOVA method for sample size estimation, we can reduce the sample size by approximately $25 \%$ (i.e. $1-0.5^{2}$ ) compared to the POST treatment means method.

Should the method of sample size estimation mirror the proposed method of statistical analysis (of the outcome data)? That is, if an ANCOVA model is likely to be used in the statistical analysis of the collected outcome data, should an ANCOVA method that allows for the correlation also be used in the sample size estimation method? And if so, what correlation (between baseline and follow-up outcomes) should be assumed and 
used in the sample size estimation? Other factors/parameters in the sample size estimation method being unchanged, an assumed correlation of 0.70 (between baseline and follow-up outcomes) means that we can halve the require sample size at the study design stage, if we used an ANCOVA method compared to a comparison of POST treatment means method. It is, however, paramount to assess how realistic a correlation of 0.50 or 0.70 between baseline and post-randomisation outcomes is, and to make evidence-based assumptions on these values, as an overestimated correlation could result in an underpowered study. The aim of this paper is to estimate the observed correlations between baseline and post-randomisation follow-up PROMs from a number of RCTs, bridging a gap in the evidence.

\section{Methods}

\section{Data sources}

This was a secondary analysis of RCTs with continuous patient-reported outcomes (both primary and secondary) undertaken in the School of Health and Related Research (ScHARR) at the University of Sheffield published between 1998 and 2019. Secondary ethics approval was gained through the University of Sheffield ScHARR Ethics Committee (Reference 024041).

\section{Statistical analysis}

For each included trial, the correlation between baseline and post-randomisation outcomes was calculated using the Pearson correlation coefficient [7]. Given a set of $n$ pairs of observations $\left(x_{1}, y_{1}\right),\left(x_{2}, y_{2}\right), \ldots,\left(x_{n}, y_{n}\right)$, with means $\bar{x}$ and $\bar{y}$ respectively, then the Pearson correlation coefficient $r$ is given by:

$$
r=\frac{\sum_{i=1}^{n}\left(y_{i}-\bar{y}\right)\left(x_{i}-\bar{x}\right)}{\sqrt{\sum_{i=1}^{n}\left(y_{i}-\bar{y}\right)^{2} \sum_{i=1}^{n}\left(x_{i}-\bar{x}\right)^{2}}}
$$

with a standard error $\operatorname{SE}(r)=\operatorname{SE}(r)=\sqrt{\frac{1-r^{2}}{n-2}}$.

A variety of summary statistics for the baseline and post-randomisation correlations were calculated, including (1) the unweighted sample mean and median; (2) a weighted sample mean, using the fixed effect inverse variance method [4], and (3) a sample mean with allowance for clustering by trial derived from a multilevel mixed-effects linear model with a random effect for the trial using restricted maximum likelihood estimation (REML) [8]. The correlations were calculated overall and then split by trial, outcome and time point.

\section{Results}

Trials

Table 1 shows a summary of the 20 RCTs included in the analysis. Various outcome measures were used in the trials for both the primary and secondary outcomes. Table 2 provides a brief description of the outcome measures and how they were scaled. Three of the outcome measures, the Clinical Outcomes in Routine Evaluation Outcome Measure (CORE-OM), Pelvic Organ Prolapse/ Urinary Incontinence Sexual Questionnaire (PISQ-31) and SPADI, have a total score and various subscales: both were included in the analysis. The 20 included RCTs had sample sizes (at baseline) ranging from 49 to 2659 participants. The time points for the postrandomisation to follow-up assessments ranged from 7 days to 24 months. The maximum sample size for the baseline follow-up correlations ranged from 39 to 2659 participants. Four-hundred and sixty-four correlations between baseline and follow-up were estimated in the 20 trials. Table 1 shows, for example, that the Leg Ulcer trial (Trial 1) had 9 outcomes all assessed at 2 postrandomisation time points ( 3 and 12 months), giving a total of $2 \times 9=18$ correlations. The median number of outcomes per trial was 9 and ranged from 1 (in the $3 \mathrm{Mg}$ trial) to 15 (AIM-High, PLINY and IPSU). The median number of correlations calculated per trial was 16.5 and ranged from 1 (in the $3 \mathrm{Mg}$ trial) to 65 (in the DiPALS trial). The median number of post-randomisation follow-up time points across the 20 trials was 2.5 and ranged from 1 to 6 .

\section{Correlation}

Figure 2 shows a histogram of the 464 estimated baseline to follow-up correlations. The histogram is reasonably symmetrical, and the overall mean correlation was 0.50 (median of 0.51 ). The baseline to follow-up correlations ranged from -0.13 to 0.91 with an interquartile range of 0.41 to 0.60 . Since the sample sizes for the trials varied from 49 to 2659 participants, a weighted estimate of the mean correlation, using the inverse variance method, was 0.51 . Since the 464 correlation estimates were from 20 trials and the correlations were nested or clustered with trials, the estimated mean correlation after allowing for clustering by trial, using a multilevel mixed-effects linear regression model (with a random effect or intercept for the trial), was 0.49 (95\% confidence interval [CI] 0.45 to 0.53 ). These other summary estimates were very similar to the simple unweighted mean value of 0.50 .

Table 3 shows the baseline to post-randomisation follow-up correlations aggregated by trial. The largest average correlations per trial showed a mean of 0.67 observed in the PLINY trial; the lowest average correlations were observed in the POLAR trial. The trial with the 
Table 1 Summary of the 20 randomised controlled trials

\begin{tabular}{|c|c|c|c|c|c|c|c|c|c|c|c|c|}
\hline & Trial name & Trial population & $\begin{array}{l}\text { Age } \\
\text { range } \\
\text { (years) }\end{array}$ & $\begin{array}{l}\text { Outcome } \\
\text { measures }\end{array}$ & $\begin{array}{l}\text { No. of } \\
\text { outcomes }\end{array}$ & $\begin{array}{l}\text { Time points } \\
\text { post- } \\
\text { randomisation }\end{array}$ & $\begin{array}{l}\text { No. of } \\
\text { time } \\
\text { points }\end{array}$ & $\begin{array}{l}\text { No. of } \\
\text { correlations }\end{array}$ & $\begin{array}{l}\text { Sample } \\
\text { size at } \\
\text { baseline }\end{array}$ & $\begin{array}{l}\operatorname{Max} \\
N^{\mathrm{a}}\end{array}$ & Reference & $\begin{array}{l}\text { Year of } \\
\text { publication }\end{array}$ \\
\hline 1 & Leg Ulcer & Leg ulcers & $\begin{array}{l}32 \text { to } \\
97\end{array}$ & EQ-5D, SF-36 & 9 & 3,12 months & 2 & 18 & 233 & 200 & [9] & 1998 \\
\hline 2 & NAMEIT & $\begin{array}{l}\text { Early severe } \\
\text { rheumatoid } \\
\text { arthritis }\end{array}$ & $\begin{array}{l}18 \text { to } \\
75\end{array}$ & SF-36, SF-6D & 9 & $\begin{array}{l}2,4,6,8,10 \\
12 \text { months }\end{array}$ & 6 & 54 & 222 & 222 & [10] & 2000 \\
\hline 3 & $\begin{array}{l}\text { Homeopathy } \\
\text { for CFS }\end{array}$ & $\begin{array}{l}\text { Chronic fatigue } \\
\text { syndrome (CFS) }\end{array}$ & $\begin{array}{l}20 \text { to } \\
62\end{array}$ & MFI & 5 & 6 months & 1 & 5 & 103 & 85 & [11] & 2004 \\
\hline 4 & Acupuncture & Low back pain & $\begin{array}{l}20 \text { to } \\
64\end{array}$ & SF-36 & 8 & $\begin{array}{l}3,12,24 \\
\text { months }\end{array}$ & 3 & 24 & 239 & 217 & [12] & 2005 \\
\hline 5 & $\begin{array}{l}\text { Knee } \\
\text { Replacement }\end{array}$ & $\begin{array}{l}\text { Osteoarthritis } \\
\text { patients } \\
\text { undergoing } \\
\text { total knee } \\
\text { replacement }\end{array}$ & $\begin{array}{l}51 \text { to } \\
92\end{array}$ & $\begin{array}{l}\text { SF-36, } \\
\text { WOMAC }\end{array}$ & 14 & 3 months & 1 & 14 & 151 & 114 & [13] & 2005 \\
\hline 6 & FED & $\begin{array}{l}\text { Older (aged } \geq \\
65 \text { ) hospitalised } \\
\text { patients with } \\
\text { acute illness }\end{array}$ & $\begin{array}{l}65 \text { to } \\
93\end{array}$ & Barthel, SF-36 & 9 & $1.5,6$ months & 2 & 18 & 445 & 225 & [14] & 2006 \\
\hline 7 & AIM-High & $\begin{array}{l}\text { Malignant } \\
\text { melanoma }\end{array}$ & $\begin{array}{l}18 \text { to } \\
77\end{array}$ & $\begin{array}{l}\text { EORTC QLQ- } \\
\text { C30 }\end{array}$ & 15 & $\begin{array}{l}6,12,18,24 \\
\text { months }\end{array}$ & 4 & 60 & 444 & 392 & [15] & 2006 \\
\hline 8 & PONDER & New mothers & $\begin{array}{l}18 \text { to } \\
45\end{array}$ & $\begin{array}{l}\text { CORE-OM, } \\
\text { EPDS, , SF-36, } \\
\text { SF-6D }\end{array}$ & 9 & $\begin{array}{l}4.5,10.5,16.5 \\
\text { months }\end{array}$ & 3 & 26 & 2659 & 2659 & [16] & 2009 \\
\hline 9 & COPD & $\begin{array}{l}\text { Chronic } \\
\text { obstructive } \\
\text { pulmonary } \\
\text { disease (COPD) }\end{array}$ & $\begin{array}{l}49 \text { to } \\
86\end{array}$ & $\begin{array}{l}\text { EQ-5D, SF-36, } \\
\text { SF-6D }\end{array}$ & 12 & $\begin{array}{l}2,6,12,18 \\
\text { months }\end{array}$ & 4 & 48 & 238 & 172 & [17] & 2010 \\
\hline 10 & Corn Plasters & Foot corns & $\begin{array}{l}18 \text { to } \\
90\end{array}$ & $\begin{array}{l}\text { EQ-5D, EQ- } \\
\text { 5D VAS, VAS } \\
\text { Pain }\end{array}$ & 3 & $\begin{array}{l}3,6,9,12 \\
\text { months }\end{array}$ & 4 & 12 & 201 & 182 & [18] & 2013 \\
\hline 11 & PLINY & $\begin{array}{l}\text { Independently } \\
\text { living older } \\
\text { people (aged } \\
\geq 75 \text { ) }\end{array}$ & $\begin{array}{l}75 \text { to } \\
95\end{array}$ & $\begin{array}{l}\text { EQ-5D, EQ- } \\
\text { 5D VAS, } \\
\text { GSES, ONS } \\
\text { Well-being, } \\
\text { PHQ-9, SF-36 }\end{array}$ & 15 & 6 months & 1 & 15 & 157 & 56 & [19] & 2014 \\
\hline 12 & $3 \mathrm{Mg}$ & $\begin{array}{l}\text { Adults with } \\
\text { acute severe } \\
\text { asthma in the } \\
\text { emergency } \\
\text { department }\end{array}$ & $\begin{array}{l}16 \text { to } \\
88\end{array}$ & EQ-5D & 1 & 1 month & 1 & 1 & 932 & 437 & [20] & 2014 \\
\hline 13 & SELF & $\begin{array}{l}\text { Shoulder } \\
\text { rotator cuff } \\
\text { tendinopathy }\end{array}$ & $\begin{array}{l}23 \text { to } \\
83\end{array}$ & SPADI & 3 & $\begin{array}{l}3,6,12 \\
\text { months }\end{array}$ & 3 & 9 & 85 & 59 & {$[6]$} & 2016 \\
\hline 14 & BEADS & $\begin{array}{l}\text { Post-stroke } \\
\text { depression }\end{array}$ & $\begin{array}{l}31 \text { to } \\
97\end{array}$ & $\begin{array}{l}\text { EQ-5D, EQ- } \\
5 \mathrm{D} V A S, \text { PHQ- } \\
9\end{array}$ & 3 & 6 months & 1 & 3 & 49 & 39 & {$[21]$} & 2016 \\
\hline 15 & DiPALS & $\begin{array}{l}\text { Amyotrophic } \\
\text { lateral sclerosis } \\
\text { (ALS) }\end{array}$ & $\begin{array}{l}23 \text { to } \\
83\end{array}$ & $\begin{array}{l}\text { EQ-5D, } \\
\text { SAQLI, SF-36 }\end{array}$ & 13 & $\begin{array}{l}2,3,6,9,12 \\
\text { months }\end{array}$ & 5 & 65 & 74 & 55 & [22] & 2016 \\
\hline 16 & $\begin{array}{l}\text { Lifestyle } \\
\text { Matters }\end{array}$ & $\begin{array}{l}\text { Independently } \\
\text { living older } \\
\text { people (aged } \\
\geq 65 \text { ) }\end{array}$ & $\begin{array}{l}65 \text { to } \\
92\end{array}$ & $\begin{array}{l}\text { EQ-5D, EQ- } \\
\text { 5D VAS, } \\
\text { GSES, PHQ-9, } \\
\text { SF-36 }\end{array}$ & 14 & 6,24 months & 2 & 28 & 288 & 262 & [23] & 2017 \\
\hline 17 & IPSU & $\begin{array}{l}\text { Women with } \\
\text { urinary } \\
\text { incontinence } \\
\text { and sexual }\end{array}$ & $\begin{array}{l}21 \text { to } \\
70\end{array}$ & $\begin{array}{l}\text { EQ-5D, PISQ- } \\
31, \text { SF-36 }\end{array}$ & 15 & 6 months & 1 & 15 & 107 & 66 & [24] & 2018 \\
\hline
\end{tabular}


Table 1 Summary of the 20 randomised controlled trials (Continued)

\begin{tabular}{|c|c|c|c|c|c|c|c|c|c|c|c|c|}
\hline & Trial name & Trial population & $\begin{array}{l}\text { Age } \\
\text { range } \\
\text { (years) }\end{array}$ & $\begin{array}{l}\text { Outcome } \\
\text { measures }\end{array}$ & $\begin{array}{l}\text { No. of } \\
\text { outcomes }\end{array}$ & $\begin{array}{l}\text { Time points } \\
\text { post- } \\
\text { randomisation }\end{array}$ & $\begin{array}{l}\text { No. of } \\
\text { time } \\
\text { points }\end{array}$ & $\begin{array}{l}\text { No. of } \\
\text { correlations }\end{array}$ & $\begin{array}{l}\text { Sample } \\
\text { size at } \\
\text { baseline }\end{array}$ & $\begin{array}{l}\operatorname{Max} \\
N^{a}\end{array}$ & Reference & $\begin{array}{l}\text { Year of } \\
\text { publication }\end{array}$ \\
\hline & & dysfunction & & & & & & & & & & \\
\hline 18 & POLAR & $\begin{array}{l}\text { Lumbar } \\
\text { radicular } \\
\text { syndrome (LRS) }\end{array}$ & $\begin{array}{l}23 \text { to } \\
71\end{array}$ & $\begin{array}{l}\text { Back Pain } \\
\text { VAS, EQ-5D, } \\
\text { EQ-5D VAS, } \\
\text { Leg Pain VAS, } \\
\text { ODI }\end{array}$ & 5 & $\begin{array}{l}1.5,3,6 \\
\text { months }\end{array}$ & 3 & 15 & 80 & 73 & {$[25]$} & 2018 \\
\hline 19 & PRACTICE & COPD & $\begin{array}{l}40 \text { to } \\
92\end{array}$ & $\begin{array}{l}\text { EQ-5D, EQ- } \\
5 \text { D VAS }\end{array}$ & 2 & $\begin{array}{l}0.25,1,3 \\
\text { months }\end{array}$ & 3 & 6 & 55 & 42 & [26] & 2018 \\
\hline \multirow[t]{2}{*}{20} & STEPWISE & Schizophrenia & $\begin{array}{l}18 \text { to } \\
71\end{array}$ & $\begin{array}{l}\text { B-IPQ, BPRS, } \\
\text { EQ-5D, EQ- } \\
5 \text { D VAS, PHQ- } \\
9, \text { RAND SF- } \\
36\end{array}$ & 14 & 3, 12 months & 2 & 28 & 412 & 358 & {$[27]$} & 2018 \\
\hline & & & & & & & & 464 & 7173 & 5915 & & \\
\hline
\end{tabular}

${ }^{\mathrm{a}} \operatorname{Max} N$ is the maximum sample size for the baseline and post-randomisation follow-up correlations

${ }^{b}$ For the PoNDER trial the EPDS was measured at baseline and at 4.5 and 10.5 months post-randomisation

Abbreviations: Barthel Barthel Index for Activities of Daily Living (ADL), B-IPQ Brief Illness Perception Questionnaire, BPRS Brief Psychiatric Rating Scale, CORE-OM Clinical Outcomes in Routine Evaluation-Outcome Measure, EORTC QLQ European Organisation for Research and Treatment of Cancer Quality of Life Questionnaire, EPDS Edinburgh Postnatal Depression Scale, EQ-5D EuroQol Five Dimension, GSES General Self-Efficacy Scale, MFI Multidimensional Fatigue Inventory, ODI Oswestry Disability Index, ONS Office for National Statistics Well-being Questionnaire, PHQ-9 Patient Health Questionnaire, PISQ-31 Pelvic Organ Prolapse/Urinary Incontinence Sexual Questionnaire, RAND SF-36 Research and Development 36-item Short Form Survey Instrument, SAQLI Sleep Apnea Quality of Life Index, SF-36 Short Form (36 item) Health Survey, SF-6D Short Form Six Dimension, SPADI Shoulder Pain and Disability Index, VAS visual analogue scale, WOMAC Western Ontario and McMaster Universities Osteoarthritis Index

widest range of correlations was the PRACTICE trial. Figure 3 shows a box and whisker plot of how the observed baseline to follow-up correlations varied across the $20 \mathrm{RCTs}$ along with the overall median correlation. There was considerable intertrial variation in the correlations, and it should be noted that some of the trials had less than or equal to six baseline to follow-up correlations estimated ( $3 \mathrm{Mg}[N=1$ outcome and correlation], BEADS $[N=3]$, Homeopathy $[N=5]$ and PRACTICE $[N=6])$.

The time points for the post-randomisation follow-up assessments ranged from 7 days to 24 months. Table 4 shows the baseline to post-randomisation follow-up correlations by post-randomisation follow-up time point. Figure 4 shows a scatter plot of the baseline to follow-up correlations by post-randomisation follow-up time point for the 464 correlations from the 20 trials. Although it is not obvious from the scatter plot, a multilevel mixedeffects linear regression model (with a random intercept for the trial) suggests a small decline in the baseline to post-randomisation follow-up correlations the further the time points are apart. The estimated regression coefficient from the model was -0.003 (95\% CI -0.006 to $0.001 ; P=0.005)$. This implies that for every unit or 1 month increase in the time from baseline to the postrandomisation follow-up the correlation declines by 0.003 point. Figures 5 and 6 show how the correlations change over time for the Short Form Health Survey (SF36) outcomes (282 correlations and 12 trials) and the EuroQol five dimension scale (EQ-5D) Utility score outcome (29 correlations and 12 trials). A similar pattern to the overall pattern is observed for these specific outcomes with a small decline (0.003 for the SF-36 and 0.002 for the EQ-5D) in baseline to follow-up correlations over time.

Table 5 shows the baseline to post-randomisation correlations by outcome. The SF-36 was the most popular outcome and used in 12 out of the 20 trials. The correlations for SF-36 outcomes and its various dimensions (12 trials and $n=282$ correlations) showed a mean of 0.51 (median 0.53), range 0.06 to 0.91 . The second most popular outcome was the EQ-5D, which was used in 12 of the trials as well. Correlations for EQ-5D outcomes only (12 trials and $n=50$ correlations) showed a mean of 0.49 (median 0.51 ), range -0.13 to 087 . Three of the outcome measures, the CORE-OM, PISQ-31 and SPADI, in Table 5 have a total score and various subscales. There was no clear pattern in the correlations and no reliable evidence that the total scale score correlated more highly than an individual subscale score.

\section{Discussion}

The 20 reviewed RCTs had sample sizes, at baseline, ranging from 49 to 2659 participants. The time points for the post-randomisation follow-up assessments ranged from 7 days to 24 months; 464 correlations between baseline and follow-up were estimated; the mean correlation was 0.50 (median 0.51 ; SD 0.15 ; range -0.13 to 0.91$)$. 
Table 2 Description of the outcome measures used in 20 randomised controlled trials and how they are scaled/scored

\begin{tabular}{|c|c|c|c|c|c|}
\hline & Outcome name & Trials & Score range & Correlations & Reference \\
\hline 1 & B-IPQ & 1 & 0 to 10 & 2 & [28] \\
\hline 2 & Back Pain VAS & 1 & 0 to 10 & 3 & [29] \\
\hline 3 & Barthel score & 1 & 0 to 20 & 2 & [30] \\
\hline 4 & BPRS & 1 & 0 to 126 & 2 & [31] \\
\hline 5 & CORE Life functioning dimension & 1 & 0 to 4 & 3 & [32] \\
\hline 6 & CORE Risk/harm dimension & 1 & 0 to 4 & 3 & \\
\hline 7 & CORE Problems/symptoms dimension & 1 & 0 to 4 & 3 & \\
\hline 8 & CORE Subjective well-being dimension & 1 & 0 to 4 & 3 & \\
\hline 9 & CORE total score & 1 & 0 to 4 & 3 & \\
\hline 10 & EORTC Appetite Loss & 1 & 0 to 100 & 4 & [33] \\
\hline 11 & EORTC Cognitive Functioning & 1 & 0 to 100 & 4 & \\
\hline 12 & EORTC Constipation & 1 & 0 to 100 & 4 & \\
\hline 13 & EORTC Diarrhoea & 1 & 0 to 100 & 4 & \\
\hline 14 & EORTC Dyspnoea & 1 & 0 to 100 & 4 & \\
\hline 15 & EORTC Emotional Functioning & 1 & 0 to 100 & 4 & \\
\hline 16 & EORTC Fatigue & 1 & 0 to 100 & 4 & \\
\hline 17 & EORTC Financial Difficulties & 1 & 0 to 100 & 4 & \\
\hline 18 & EORTC Insomnia & 1 & 0 to 100 & 4 & \\
\hline 19 & EORTC Nausea & 1 & 0 to 100 & 4 & \\
\hline 20 & EORTC Pain & 1 & 0 to 100 & 4 & \\
\hline 21 & EORTC Physical Functioning & 1 & 0 to 100 & 4 & \\
\hline 22 & EORTC QoL & 1 & 0 to 100 & 4 & \\
\hline 23 & EORTC Role Functioning & 1 & 0 to 100 & 4 & \\
\hline 24 & EORTC Social Functioning & 1 & 0 to 100 & 4 & \\
\hline 25 & EPDS & 1 & 0 to 30 & 2 & [34] \\
\hline 26 & EQ-5D Utility score & 12 & -0.56 to 1.00 & 29 & {$[35]$} \\
\hline 27 & EQ-5D VAS & 8 & 0 to 100 & 21 & {$[36]$} \\
\hline 28 & GSES & 2 & 10 to 40 & 3 & {$[37]$} \\
\hline 29 & Leg Pain VAS & 1 & 0 to 10 & 3 & [29] \\
\hline 30 & MFI General Fatigue & 1 & 4 to 20 & 1 & {$[38]$} \\
\hline 31 & MFI Mental Fatigue & 1 & 4 to 20 & 1 & \\
\hline 32 & MFI Physical Fatigue & 1 & 4 to 20 & 1 & \\
\hline 33 & MFI Reduced Activity & 1 & 4 to 20 & 1 & \\
\hline 34 & MFI Reduced Motivation & 1 & 4 to 20 & 1 & \\
\hline 35 & ODI & 1 & 0 to 100 & 3 & [39] \\
\hline 36 & ONS Well-Being & 1 & 0 to 40 & 1 & {$[40]$} \\
\hline 37 & PHQ-9 & 4 & 0 to 27 & 6 & [41] \\
\hline 38 & PISQ-31 Behaviour/Emotion & 1 & 0 to 61 & 1 & [42] \\
\hline 39 & PISQ-31 Partner-Related Factor & 1 & 0 to 24 & 1 & \\
\hline 40 & PISQ-31 Physical Factor & 1 & 0 to 40 & 1 & \\
\hline 41 & PISQ-31 total score & 1 & 0 to 125 & 1 & \\
\hline 42 & SF-36 General Health & 11 & 0 to 100 & 29 & [43] \\
\hline 43 & SF-36 Mental Health & 11 & 1 to 100 & 29 & \\
\hline 44 & SF-36 Pain & 11 & 1 to 100 & 29 & \\
\hline
\end{tabular}


Table 2 Description of the outcome measures used in 20 randomised controlled trials and how they are scaled/scored (Continued)

\begin{tabular}{|c|c|c|c|c|c|}
\hline & Outcome name & Trials & Score range & Correlations & Reference \\
\hline 45 & SF-36 Physical Functioning & 11 & 1 to 100 & 29 & \\
\hline 46 & SF-36 Role-Emotional & 11 & 1 to 100 & 29 & \\
\hline 47 & SF-36 Role-Physical & 11 & 1 to 100 & 29 & \\
\hline 48 & SF-36 Social Functioning & 11 & 1 to 100 & 29 & \\
\hline 49 & SF-36 Vitality & 11 & 1 to 100 & 29 & \\
\hline 50 & SF-36 Health Change & 1 & 1 to 100 & 2 & \\
\hline 51 & SF-36 Mental Component Summary & 7 & NBS & 17 & [44] \\
\hline 52 & SF-36 Physical Component Summary & 7 & NBS & 17 & \\
\hline 53 & $S F-6 D$ & 4 & 0.29 to 1.00 & 14 & [45] \\
\hline 54 & Sleep Apnoea QoL & 1 & 1 to 7 & 5 & [46] \\
\hline 55 & SPADI Disability & 1 & 0 to 100 & 3 & [47] \\
\hline 56 & SPADI Pain & 1 & 0 to 100 & 3 & \\
\hline 57 & SPADI total score & 1 & 0 to 100 & 3 & \\
\hline 58 & VAS Pain & 1 & 0 to 10 & 4 & [48] \\
\hline 59 & WOMAC Pain & 1 & 0 to 20 & 1 & [49] \\
\hline 60 & WOMAC Physical Function & 1 & 0 to 68 & 1 & \\
\hline 61 & WOMAC Stiffness & 1 & 0 to 8 & 1 & \\
\hline
\end{tabular}

NBS norm-based scoring: scores are standardised to have a mean of 50 and SD of 10

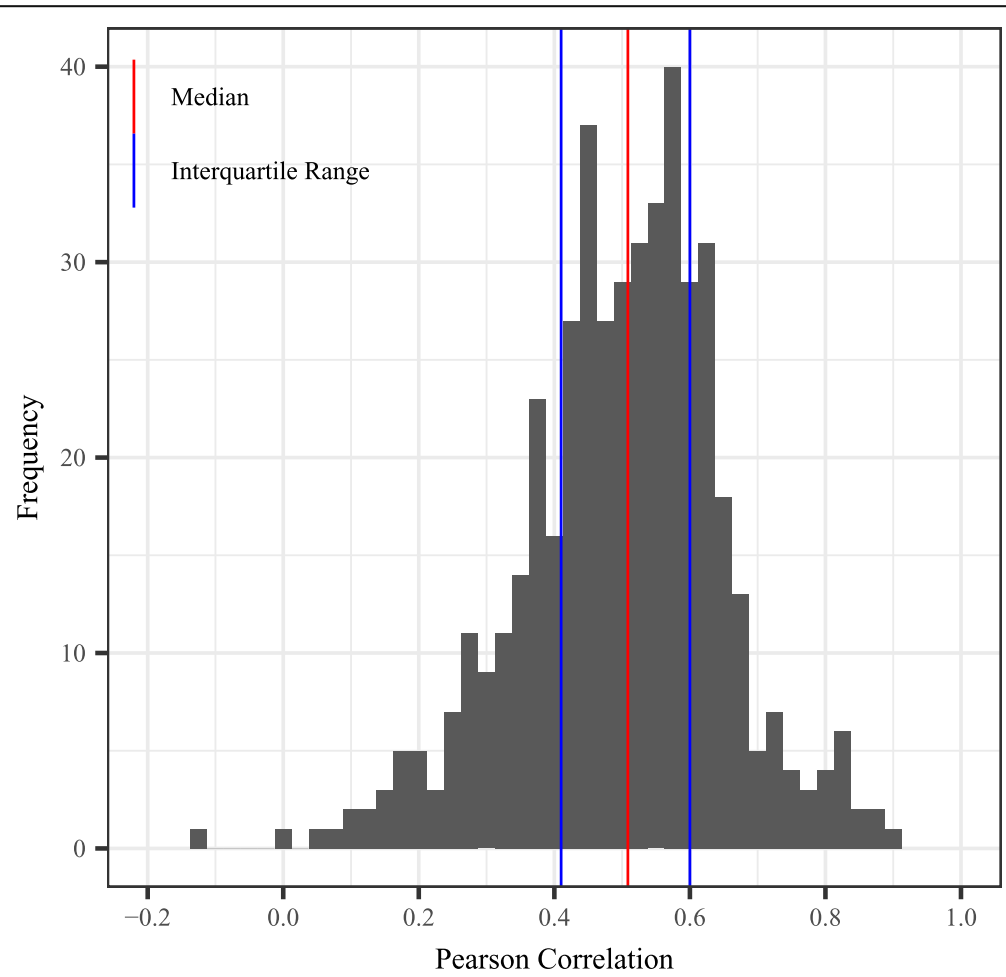

(between baseline and post-randomisation follow-up)

Fig. 2 Histogram of $n=464$ correlations with overall median, 25th and 75th percentiles 
Table 3 Baseline to post-randomisation follow-up correlations by trial

\begin{tabular}{|c|c|c|c|c|c|c|}
\hline \multirow[t]{2}{*}{ Trial name } & \multicolumn{6}{|c|}{ Pearson baseline to post-randomisation follow-up correlation } \\
\hline & Mean & Median & No. of correlations & SD & Minimum & Maximum \\
\hline Leg Ulcer & 0.48 & 0.5 & $N=18$ & 0.13 & 0.23 & 0.71 \\
\hline NAMEIT & 0.46 & 0.46 & $N=54$ & 0.1 & 0.21 & 0.63 \\
\hline Homeopathy for CFS & 0.5 & 0.53 & $N=5$ & 0.19 & 0.18 & 0.65 \\
\hline Acupuncture & 0.44 & 0.45 & $N=24$ & 0.12 & 0.2 & 0.62 \\
\hline Knee Replacement & 0.45 & 0.48 & $N=14$ & 0.16 & 0.09 & 0.65 \\
\hline FED & 0.5 & 0.56 & $N=18$ & 0.12 & 0.32 & 0.7 \\
\hline AlM-High & 0.46 & 0.49 & $N=60$ & 0.14 & 0.16 & 0.74 \\
\hline PONDER & 0.44 & 0.47 & $N=26$ & 0.11 & 0.19 & 0.58 \\
\hline COPD & 0.53 & 0.54 & $N=48$ & 0.08 & 0.37 & 0.68 \\
\hline Corn Plaster & 0.45 & 0.45 & $N=12$ & 0.06 & 0.33 & 0.53 \\
\hline PLINY & 0.67 & 0.74 & $N=15$ & 0.15 & 0.41 & 0.87 \\
\hline $3 \mathrm{Mg}$ & 0.39 & 0.39 & $N=1$ & - & 0.39 & 0.39 \\
\hline SELF & 0.44 & 0.44 & $N=9$ & 0.07 & 0.31 & 0.54 \\
\hline BEADS & 0.46 & 0.53 & $N=3$ & 0.3 & 0.14 & 0.71 \\
\hline DiPALS & 0.54 & 0.57 & $N=65$ & 0.18 & 0.01 & 0.91 \\
\hline Lifestyle Matters & 0.66 & 0.64 & $N=28$ & 0.11 & 0.45 & 0.88 \\
\hline IPSU & 0.57 & 0.63 & $N=15$ & 0.13 & 0.34 & 0.73 \\
\hline POLAR & 0.32 & 0.36 & $N=15$ & 0.14 & 0.04 & 0.53 \\
\hline PRACTICE & 0.36 & 0.38 & $N=6$ & 0.36 & -0.13 & 0.79 \\
\hline STEPWISE & 0.53 & 0.56 & $N=28$ & 0.13 & 0.24 & 0.72 \\
\hline Total ${ }^{a}$ & 0.5 & 0.51 & $N=464$ & 0.15 & -0.13 & 0.91 \\
\hline
\end{tabular}

${ }^{a}$ The summary statistics for the total row are calculated from 464 correlations

The 20 RCTs included in this study were a convenience sample of trials and data and may not be representative of the population of all trials with PROMs. However, they include a wide range of populations and disease areas, a variety of different interventions and outcomes that are not untypical of other published trials. We also reviewed detailed reports of 181 RCTs published in the National Institute for Health Research (NIHR) Health Technology Assessment (HTA) journal from 2004 to the end of July 2017 and found 11 NIHR HTA reports (and 12 outcomes) that had a sample size calculation based on the ANCOVA model [50]. For these 12 outcomes the mean baseline to follow-up correlation that was assumed and used in the subsequent sample size calculation was 0.49 (SD 0.09) and ranged from 0.31 to 0.60 . Thus, our results, with a mean correlation of 0.50 , are consistent with correlations used and published in the NIHR HTA journal.

We observed a small decline in baseline to followup correlations over time of -0.003 per month. That is, for every unit or 1-month increase in the time from baseline to the post-randomisation follow-up, the correlation declines by 0.003 point. Frison and Pocock [1] also report a slight decline in correlation amongst more distant pairs of time points postrandomisation, with the estimated slope being -0.009 per month apart. So our results are also consistent with a slight decline.

It is important to make maximum use of the information available from other related studies or extrapolation from other unrelated studies. The more precise the information, the better we can design the trial. We would recommend that researchers planning a study with PROMs as the primary outcome pay careful attention to any evidence on the validity and frequency distribution of the PROM and its dimensions.

Strictly speaking, our results and conclusions only apply to the study population and the outcome measures used in the 20 RCTs. Further empirical work is required to see whether these results hold true for other outcomes, populations and interventions. However, the PROMs in this paper share many features in common with other PROM outcomes, i.e. multidimensional, ordinal or discrete response categories with upper and lower bounds, and skewed distributions; therefore, we see no theoretical reasons why these results and conclusions may not be appropriate for other PROMs. 


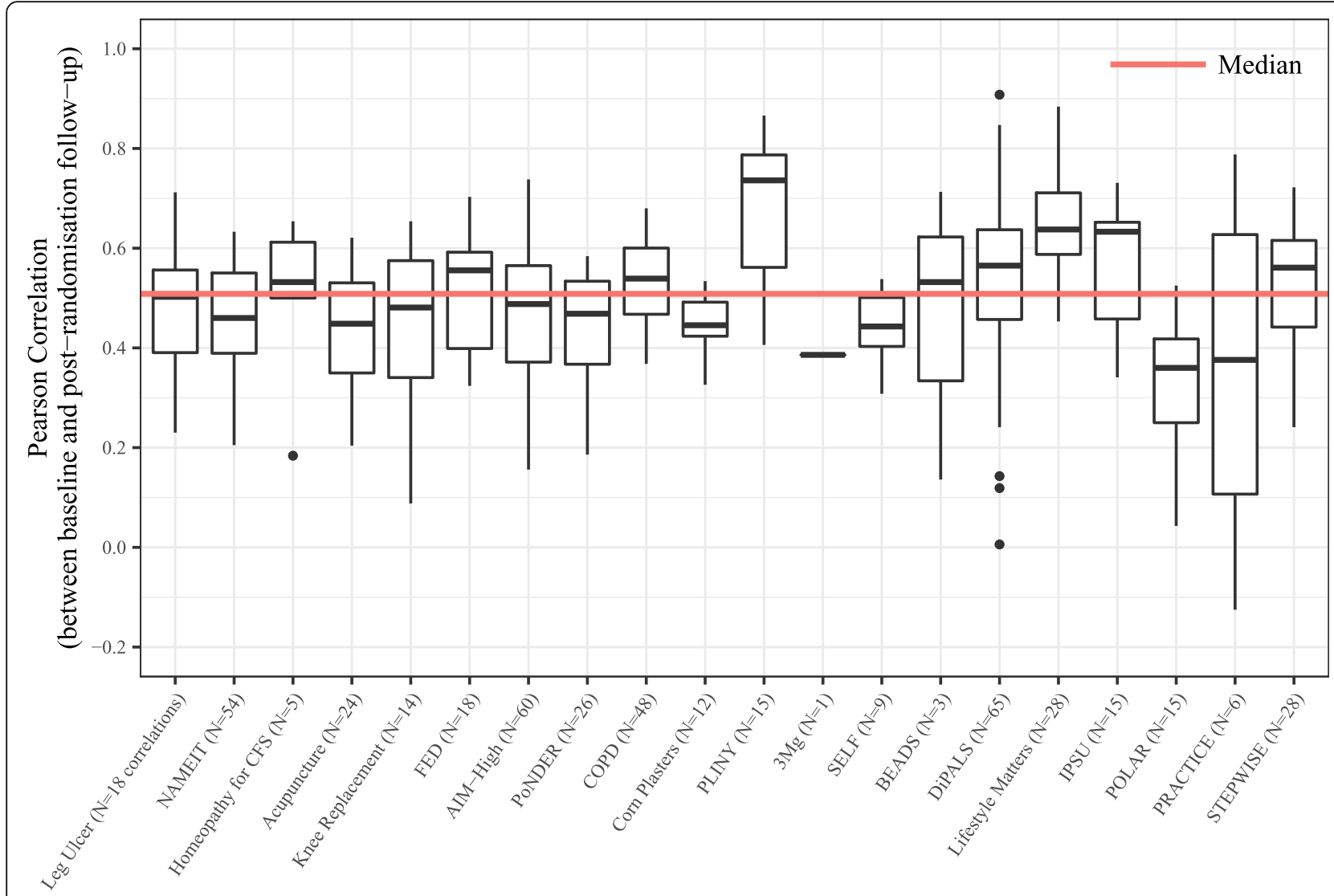

Trial

Fig. 3 Box and whisker plot of $(n=464)$ correlations by trial

Table 4 Baseline to post-randomisation follow-up correlations by post-randomisation follow-up time point

\begin{tabular}{|c|c|c|c|c|c|c|}
\hline \multirow{2}{*}{$\begin{array}{l}\text { Post- } \\
\text { randomisation } \\
\text { follow-up time } \\
\text { point (months) }\end{array}$} & \multicolumn{6}{|c|}{ Pearson baseline to post-randomisation follow-up correlation } \\
\hline & Mean & Median & SD & Minimum & Maximum & No. of correlations \\
\hline 0.25 & 0.48 & 0.48 & 0.44 & 0.17 & 0.79 & 2 \\
\hline 1 & 0.37 & 0.39 & 0.28 & 0.09 & 0.64 & 3 \\
\hline 1.5 & 0.49 & 0.45 & 0.12 & 0.33 & 0.70 & 14 \\
\hline 2 & 0.55 & 0.56 & 0.12 & 0.26 & 0.82 & 34 \\
\hline 3 & 0.48 & 0.50 & 0.15 & -0.13 & 0.72 & 71 \\
\hline 4 & 0.48 & 0.49 & 0.09 & 0.35 & 0.63 & 9 \\
\hline 4.5 & 0.48 & 0.52 & 0.09 & 0.32 & 0.58 & 9 \\
\hline 6 & 0.54 & 0.55 & 0.16 & 0.04 & 0.88 & 121 \\
\hline 8 & 0.43 & 0.44 & 0.13 & 0.21 & 0.58 & 9 \\
\hline 9 & 0.62 & 0.62 & 0.16 & 0.38 & 0.91 & 16 \\
\hline 10 & 0.45 & 0.43 & 0.08 & 0.34 & 0.58 & 9 \\
\hline 10.5 & 0.42 & 0.47 & 0.12 & 0.19 & 0.54 & 9 \\
\hline 12 & 0.46 & 0.48 & 0.14 & 0.01 & 0.72 & 86 \\
\hline 16.5 & 0.41 & 0.42 & 0.12 & 0.23 & 0.57 & 8 \\
\hline 18 & 0.47 & 0.49 & 0.13 & 0.16 & 0.67 & 27 \\
\hline 24 & 0.51 & 0.53 & 0.15 & 0.17 & 0.84 & 37 \\
\hline
\end{tabular}




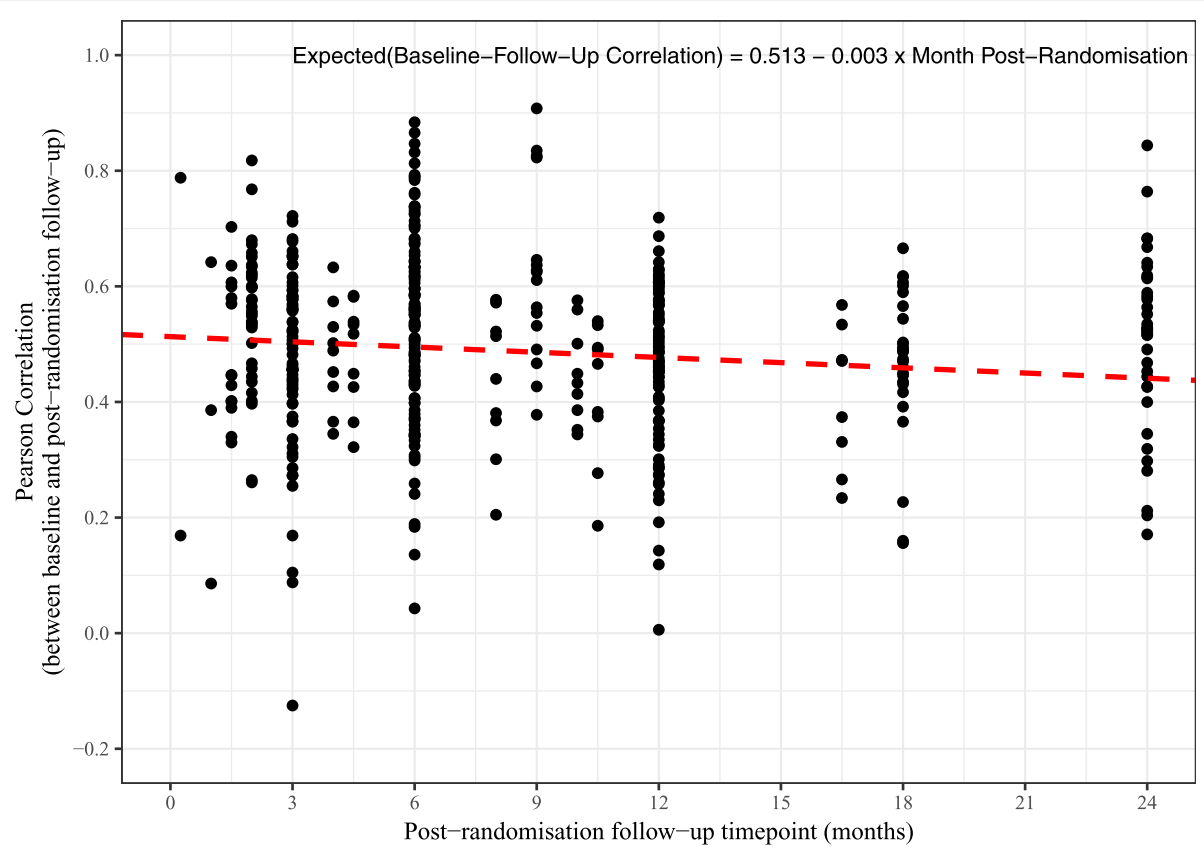

Fig. 4 Scatter plot of correlations against post-randomisation follow-up time point with regression line (464 correlations from 20 trials)

Throughout this paper, we only considered the situation where a single dimension of the PROM is used at a single endpoint. Sometimes there is more than one endpoint of interest; PROMs are typically multidimensional (e.g. the SF-36 has eight dimensions). If one of these dimensions is regarded as more important than the others, it can be named as the primary endpoint and the sample size estimates calculated accordingly. The remainder should be consigned to exploratory analyses or descriptions only.

We have also assumed a rather simple form of the alternative hypothesis that the new treatment/intervention would improve patient-reported outcomes compared to the control/standard therapy. This form of

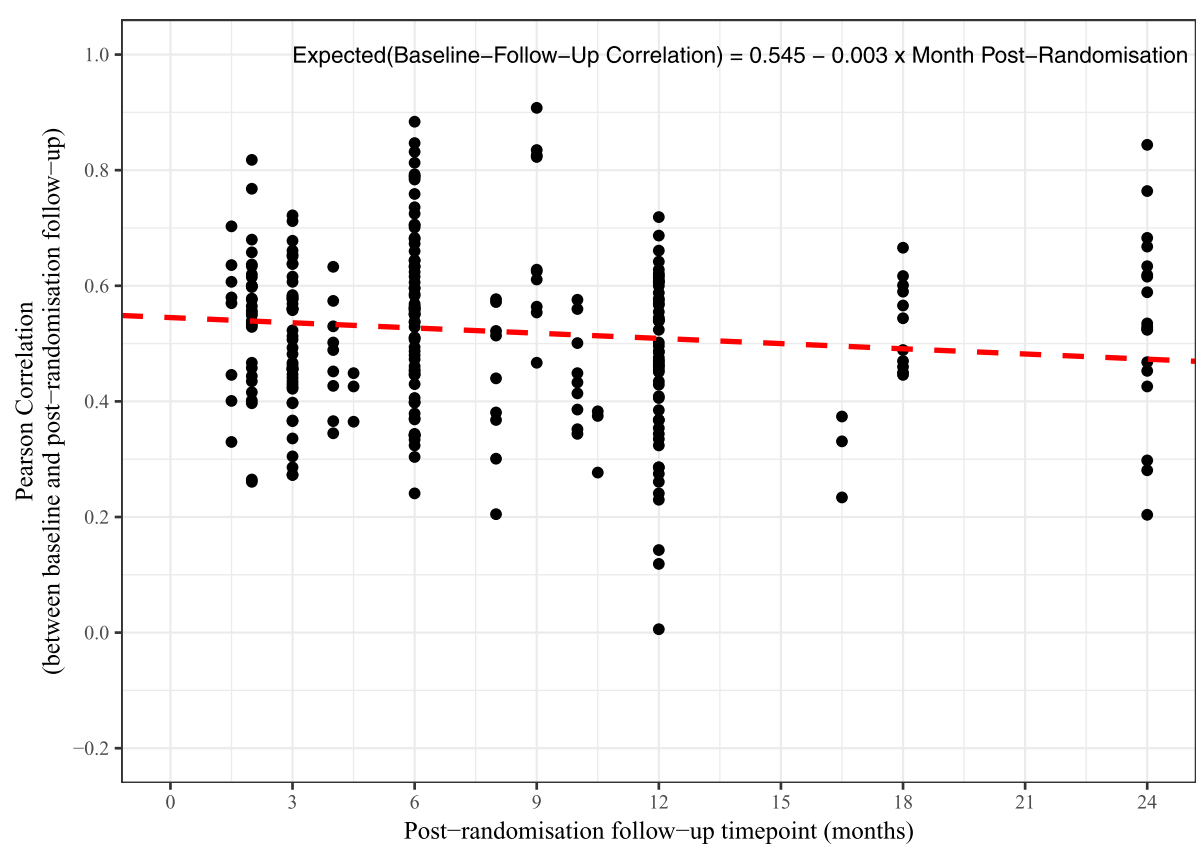

Fig. 5 Scatter plot of correlations against post-randomisation follow-up time point with regression line, SF-36 outcomes (282 correlations from 12 trials) 


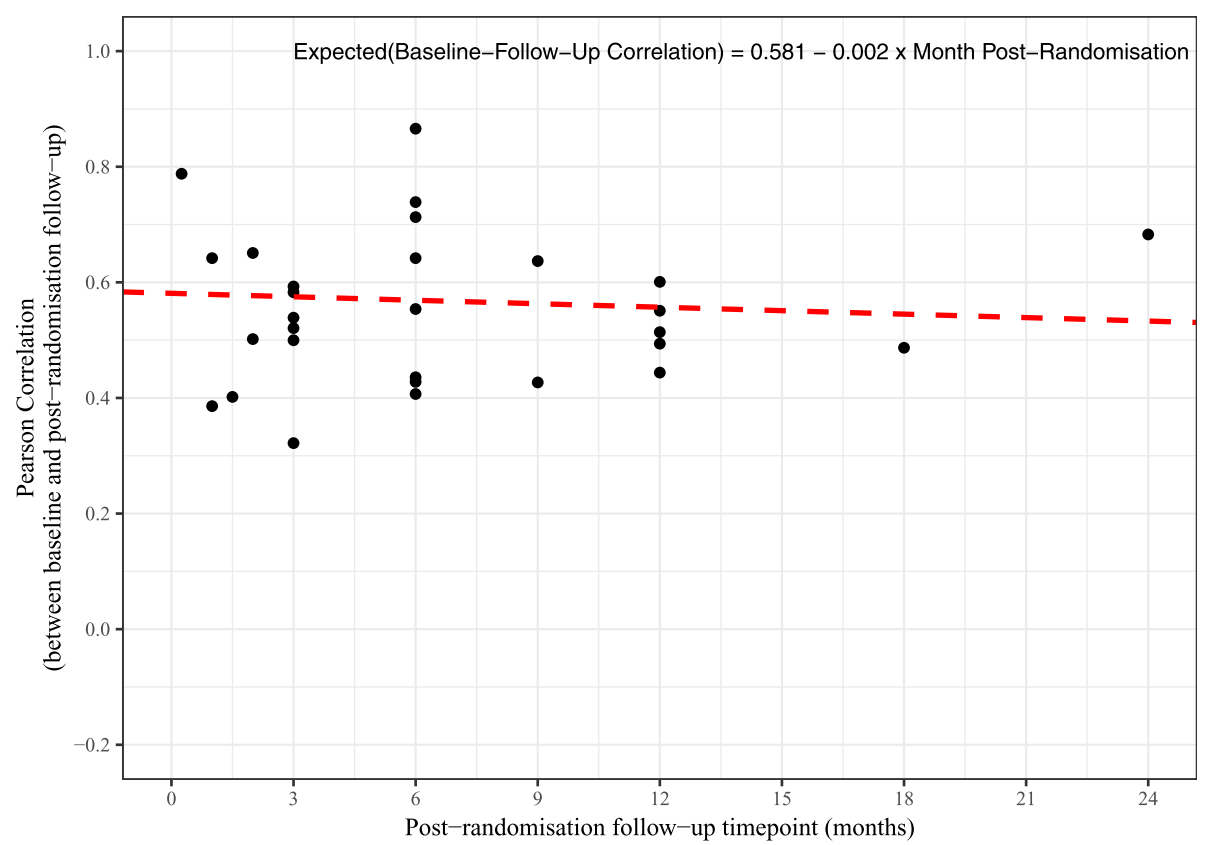

Fig. 6 Scatter plot of correlations against post-randomisation follow-up time point with regression line, EQ-5D Utility outcome (29 correlations from 12 trials)

hypothesis (superiority versus equivalence) may be more complicated than actually presented. However, the assumption of a simple form of the alternative hypothesis-that the new treatment/intervention would improve outcomes compared to the control/standard therapy-is not unrealistic for most superiority trials and is frequently used for other clinical outcomes. Walters gives a more comprehensive discussion of multiple endpoints and suggests several methods for analysing PROMs [4].

Overall, 5 of the 464 observed correlations were small (less than 0.10). Two of these small correlations came from the PRACTICE trial [26]. In this trial (PRACTICE) we observed a negative correlation of -0.13 ( $n=36$ participants) between the baseline and 3 months follow-up post-randomisation time point for the EQ-5D visual analogue scale (VAS) and 0.09 ( $n=42$ participants) between the baseline and 1 month follow-up. The correlations were based on small sample sizes ( $n=36$ and 42), and examination of the scatter plots suggested no outlying values and a random scatter. The EQ-5D VAS outcome asks respondents to rate their health today on a 0 (the worst health you can imagine) to 100 (best health you can imagine) visual analogue scale. It may be that there genuinely is no correlation in the population (of chronic obstructive pulmonary disease [COPD] patients) with this outcome.

We calculated several summary correlations to allow for clustering of the outcomes by trial and the variance or standard error of the correlation estimate. The overall summary correlation for the 464 correlations was robust to the summary measure (mean, median, weighted mean, clustered mean) and was around 0.50.

Clifton and Clifton [51] comment that baseline imbalance may occur in RCTs and that ANCOVA should be used to adjust for baseline in the analysis. Clifton et al. [52] also point out the following theoretical assumptions for using the ANCOVA method for sample size estimation: (1) the pairs of baseline and post-randomisation outcomes follow a bivariate normal distribution; (2) the values of the baseline to post-randomisation follow-up, $r$, are the same in both groups; (3) the variances or SDs of the outcomes are the same in both groups. However, ANCOVA is known to be robust to departures from the assumptions of Normality. The work of Heeren and D'Agostino [53]and Sullivan and D'Agostino [54] supports the robustness of the two independent samples $t$ test and ANCOVA when applied to three-, four- and five-point ordinal scaled data using assigned scores (like PROMs), in sample sizes as small as 20 subjects per group.

\section{Conclusions}

There is a general consistency in the correlations between the baseline and follow-up PROMs, with the majority being in the range from 0.4 to 0.6. The implications are that we can reduce the sample size in an RCT by $25 \%$ if we use an ANCOVA model, with a correlation of 0.50 , for the design and analysis. When allowing for the correlation between baseline and follow- 
Table 5 Baseline to post-randomisation follow-up correlations by outcome

\begin{tabular}{|c|c|c|c|c|c|c|}
\hline \multirow[t]{2}{*}{ Outcome } & \multicolumn{6}{|c|}{ Pearson baseline to post-randomisation follow-up correlation } \\
\hline & Mean & Median & SD & Minimum & Maximum & No. of correlations \\
\hline $\mathrm{B}-\mathrm{IPQ}$ & 0.6 & 0.6 & 0 & 0.6 & 0.61 & 2 \\
\hline BACK PAIN & 0.24 & 0.19 & 0.11 & 0.17 & 0.37 & 3 \\
\hline Barthel Score & 0.53 & 0.53 & 0.1 & 0.45 & 0.6 & 2 \\
\hline BPRS & 0.57 & 0.57 & 0.12 & 0.49 & 0.65 & 2 \\
\hline CORE Functioning Dimension & 0.56 & 0.57 & 0.02 & 0.54 & 0.58 & 3 \\
\hline CORE Risk Dimension & 0.26 & 0.27 & 0.07 & 0.19 & 0.32 & 3 \\
\hline CORE Symptoms Dimension & 0.5 & 0.49 & 0.03 & 0.47 & 0.54 & 3 \\
\hline CORE Total Score & 0.55 & 0.53 & 0.03 & 0.53 & 0.58 & 3 \\
\hline CORE Well Being Dimension & 0.5 & 0.49 & 0.03 & 0.47 & 0.53 & 3 \\
\hline EORTC Appetite Loss & 0.29 & 0.3 & 0.09 & 0.21 & 0.37 & 4 \\
\hline EORTC Cognitive Functioning & 0.49 & 0.49 & 0.08 & 0.4 & 0.59 & 4 \\
\hline EORTC Constipation & 0.39 & 0.4 & 0.08 & 0.3 & 0.48 & 4 \\
\hline EORTC Diarrhoea & 0.25 & 0.27 & 0.07 & 0.16 & 0.32 & 4 \\
\hline EORTC Dyspnoea & 0.43 & 0.44 & 0.06 & 0.35 & 0.49 & 4 \\
\hline EORTC Emotional Functioning & 0.51 & 0.5 & 0.06 & 0.46 & 0.6 & 4 \\
\hline EORTC Fatigue & 0.56 & 0.56 & 0.06 & 0.49 & 0.63 & 4 \\
\hline EORTC Financial Difficulties & 0.63 & 0.62 & 0.07 & 0.56 & 0.74 & 4 \\
\hline EORTC Insomnia & 0.44 & 0.49 & 0.12 & 0.26 & 0.52 & 4 \\
\hline EORTC Nausea & 0.21 & 0.18 & 0.06 & 0.16 & 0.3 & 4 \\
\hline EORTC Pain & 0.48 & 0.48 & 0.08 & 0.39 & 0.58 & 4 \\
\hline EORTC Physical Functioning & 0.59 & 0.58 & 0.07 & 0.52 & 0.68 & 4 \\
\hline EORTC QOL & 0.55 & 0.57 & 0.08 & 0.44 & 0.61 & 4 \\
\hline EORTC Role Functioning & 0.54 & 0.54 & 0.04 & 0.5 & 0.59 & 4 \\
\hline EORTC Social Functioning & 0.51 & 0.5 & 0.06 & 0.43 & 0.59 & 4 \\
\hline EPDS & 0.49 & 0.49 & 0.04 & 0.47 & 0.52 & 2 \\
\hline EQ-5D Utility Score & 0.55 & 0.54 & 0.13 & 0.32 & 0.87 & 29 \\
\hline EQ-5D VAS & 0.41 & 0.46 & 0.2 & -0.13 & 0.67 & 21 \\
\hline GSES & 0.52 & 0.56 & 0.08 & 0.44 & 0.58 & 3 \\
\hline LEG PAIN & 0.16 & 0.11 & 0.16 & 0.04 & 0.34 & 3 \\
\hline MFI General Fatigue & 0.18 & 0.18 & NA & 0.18 & 0.18 & 1 \\
\hline MFI Mental Fatigue & 0.53 & 0.53 & NA & 0.53 & 0.53 & 1 \\
\hline MFI Physical Fatigue & 0.5 & 0.5 & NA & 0.5 & 0.5 & 1 \\
\hline MFI Reduced Activity & 0.65 & 0.65 & NA & 0.65 & 0.65 & 1 \\
\hline MFI Reduced Motivation & 0.61 & 0.61 & NA & 0.61 & 0.61 & 1 \\
\hline ODI & 0.36 & 0.36 & 0.05 & 0.31 & 0.41 & 3 \\
\hline ONS Well-Being & 0.62 & 0.62 & NA & 0.62 & 0.62 & 1 \\
\hline PHQ9 & 0.66 & 0.66 & 0.08 & 0.53 & 0.76 & 6 \\
\hline PISQ-31 Behaviour/Emotion & 0.73 & 0.73 & NA & 0.73 & 0.73 & 1 \\
\hline PISQ-31 Partner Related Factor & 0.63 & 0.63 & NA & 0.63 & 0.63 & 1 \\
\hline PISQ-31 Physical Factor & 0.35 & 0.35 & NA & 0.35 & 0.35 & 1 \\
\hline PISQ-31 Total Score & 0.62 & 0.62 & NA & 0.62 & 0.62 & 1 \\
\hline SF-36 General Health & 0.6 & 0.58 & 0.08 & 0.49 & 0.79 & 29 \\
\hline SF-36 Mental Component Summary & 0.54 & 0.55 & 0.12 & 0.33 & 0.79 & 17 \\
\hline
\end{tabular}


Table 5 Baseline to post-randomisation follow-up correlations by outcome (Continued)

\begin{tabular}{|c|c|c|c|c|c|c|}
\hline \multirow[t]{2}{*}{ Outcome } & \multicolumn{6}{|c|}{ Pearson baseline to post-randomisation follow-up correlation } \\
\hline & Mean & Median & SD & Minimum & Maximum & No. of correlations \\
\hline SF-36 Mental Health & 0.57 & 0.57 & 0.11 & 0.37 & 0.83 & 27 \\
\hline SF-36 Pain & 0.49 & 0.51 & 0.13 & 0.2 & 0.71 & 29 \\
\hline SF-36 Physical Component Summary & 0.56 & 0.6 & 0.21 & 0.14 & 0.84 & 17 \\
\hline SF-36 Physical Functioning & 0.64 & 0.63 & 0.17 & 0.01 & 0.91 & 29 \\
\hline SF-36 Role-Emotional & 0.42 & 0.43 & 0.11 & 0.12 & 0.68 & 31 \\
\hline SF-36 Role-Physical & 0.39 & 0.35 & 0.12 & 0.21 & 0.67 & 29 \\
\hline SF-36 Social Functioning & 0.44 & 0.45 & 0.1 & 0.24 & 0.63 & 29 \\
\hline SF-36 Vitality & 0.55 & 0.53 & 0.1 & 0.43 & 0.82 & 29 \\
\hline SF-36 Health Change & 0.32 & 0.32 & 0.11 & 0.24 & 0.4 & 2 \\
\hline SF-6D & 0.5 & 0.48 & 0.09 & 0.37 & 0.64 & 14 \\
\hline Sleep Apnoea QoL & 0.56 & 0.6 & 0.12 & 0.35 & 0.65 & 5 \\
\hline SPADI & 0.47 & 0.47 & 0.03 & 0.44 & 0.5 & 3 \\
\hline SPADI Disability & 0.49 & 0.51 & 0.06 & 0.43 & 0.54 & 3 \\
\hline SPADI Pain & 0.36 & 0.38 & 0.05 & 0.31 & 0.4 & 3 \\
\hline VAS Pain & 0.41 & 0.41 & 0.07 & 0.33 & 0.48 & 4 \\
\hline WOMAC Pain & 0.26 & 0.26 & NA & 0.26 & 0.26 & 1 \\
\hline WOMAC Physical Function & 0.46 & 0.46 & NA & 0.46 & 0.46 & 1 \\
\hline WOMAC Stiffness & 0.09 & 0.09 & NA & 0.09 & 0.09 & 1 \\
\hline
\end{tabular}

up outcome in the sample size calculation, it is preferable to be conservative and use existing data that are relevant to your outcome and your population if they are available. Secondly, be wary of having an 'automatic' rule of adjusting your required sample size downwards by $25 \%$ just because you have a baseline assessment.

There is a slight decline in correlation between baseline and more distant post-randomisation follow-up time points. Finally, we would stress the importance of a sample size calculation (with all its attendant assumptions) and also stress that any such estimate is better than no sample size calculation at all, particularly in a trial protocol $[55,56]$. The mere fact of calculation of a sample size means that a number of fundamental issues have been considered: what is the main outcome variable, what is a clinically important effect, and how is it measured? The investigator is also likely to have specified the method and frequency of data analysis. Thus, protocols that are explicit about sample size are easier to evaluate in terms of scientific quality and the likelihood of achieving objectives.

\footnotetext{
Abbreviations

ANCOVA: Analysis of covariance; COPD: Chronic obstructive pulmonary disease; DE: Design effect; HTA: Health Technology Assessment; MCID: Minimum clinical important difference; NIHR: National Institute for Health Research; PROM: Patient reported outcome measure; RCT: Randomised controlled trial; ScHARR: School of Health and Related Research; SPADI: Shoulder Pain \& Disability Index; SSR: Sample size reestimation
}

\section{Acknowledgements}

Professor Walters is an NIHR Senior Investigator. The views expressed in this article are those of the author(s) and not necessarily those of the National Health Service (NHS), the NIHR or the Department of Health.

\section{Authors' contributions}

SJW is the guarantor of the study, had full access to all the data in the study and is responsible for the integrity of the data and the accuracy of the data analysis. SJW contributed to the study conception and design, acquisition of data, analysis and interpretation of data and writing of the report. IBHC contributed towards the selection, extraction and analysis of the data, as well as the drafting of the paper and graphics within it. RMJ contributed to the selection and extraction of the data, as well as the drafting of the paper. NT contributed to the selection and extraction of the data, as well as the drafting of the paper. JC contributed to the selection and extraction of the data, as well as the drafting of the paper. MTSX contributed to the selection and extraction of the data, as well as the drafting of the paper. All authors read and approved the final manuscript.

\section{Funding}

This research received no specific grant from any funding agency in any public, commercial or not-for-profit sector.

\section{Availability of data and materials}

The data set is available on request from the corresponding author at s.j. walters@sheffield.ac.uk.

\section{Ethics approval and consent to participate}

Secondary ethics approval was gained through the University of Sheffield School of Health and Related Research Ethics Committee (Reference 024041).

Consent for publication

Not applicable.

Competing interests

The authors declare that they have no competing interests. 
Received: 20 March 2019 Accepted: 20 August 2019

\section{Published online: 13 September 2019}

\section{References}

1. Frison L, Pocock SJ. Repeated measures in clinical trials: analysis using mean summary statistics and its implications for design. Stat Med. 1992;11(13): 1685-704.

2. Altman DG, Gardner MJ, Martin J. Statistics with confidence: confidence intervals and statistical guidelines. London: BMJ Books; 2000.

3. Walters SJ. Sample size and power estimation for studies with health related quality of life outcomes: a comparison of four methods using the SF-36. Health Qual Life Outcomes. 2004;2:26.

4. Walters SJ. Quality of life outcomes in clinical trials and health-care evaluation:a practical guide to analysis and interpretation. Chichester: Wiley; 2009. p. 1-365.

5. Machin D, Campbell MJ, Tan SB, Tan SH. Sample sizes for clinical, laboratory and epidemiology studies. 4th ed. Chichester: Wiley-Blackwell; 2018.

6. Littlewood C, Bateman M, Brown K, Bury J, Mawson S, May S, et al. A selfmanaged single exercise programme versus usual physiotherapy treatment for rotator cuff tendinopathy: a randomised controlled trial (the SELF study). Clin Rehabil. 2016;30(7):686-96.

7. Campbell MJ, Machin D, Walters SJ. Medical statistics: a textbook for the health sciences. 4th edition. Chichester: Wiley; 2007.

8. Campbell MJ, Walters SJ. How to design, analyse and report cluster randomised trials in medicine and health related research. Chichester: Wiley-Blackwell; 2014.

9. Morrell CJ, Walters SJ, Dixon S, Collins KA, Brereton LML, Peters J, et al. Cost effectiveness of community leg ulcer clinics: Randomised controlled trial. $\mathrm{Br}$ Med J. 1998:316(7143):1487-91.

10. Jack DS, Prestele H, Bakshi R. Clinical Study Report. A double-blind, randomised, controlled study to compare methotrexate plus cyclosporine $\mathrm{A} /$ neoral vs. methotrexate plus placebo in subjects with early severe rheumatoid arthritis. Basel, Switzerland; 2000

11. Weatherley-Jones E, Nicholl JP, Thomas KJ, Parry GJ, McKendrick MW, Green ST, et al. A randomised, controlled, triple-blind trial of the efficacy of homeopathic treatment for chronic fatigue syndrome. J Psychosom Res. 2004;56(2):189-97.

12. Thomas KJ, MacPherson H, Ratcliffe J, Thorpe L, Brazier J, Campbell M, et al. Longer term clinical and economic benefits of offering acupuncture care to patients with chronic low back pain. Health Technol Assess. 2005;9(32):1-109.

13. Mitchell C, Walker J, Walters S, Morgan AB, Binns T, Mathers N. Costs and effectiveness of pre- and post-operative home physiotherapy for total knee replacement: randomized controlled trial. J Eval Clin Pract. 2005;11(3):283-92.

14. Gariballa S, Forster S, Walters S, Powers H. A randomized, double-blind, placebo-controlled trial of nutritional supplementation during acute illness. Am J Med. 2006;119(8):693-9.

15. Dixon S, Walters SJ, Turner L, Hancock BW. Quality of life and costeffectiveness of interferon-alpha in malignant melanoma: results from randomised trial. Br J Cancer. 2006;94(4):492-8.

16. Morrell CJ, Slade P, Warner R, Paley G, Dixon S, Walters SJ, et al. Clinical effectiveness of health visitor training in psychologically informed approaches for depression in postnatal women: pragmatic cluster randomised trial in primary care. BMJ. 2009:338(7689):a3045.

17. Waterhouse JC, Walters SJ, Oluboyede $Y$, Lawson RA. A randomised $2 \times 2$ trial of community versus hospital pulmonary rehabilitation, followed by telephone or conventional follow-up. Health Technol Assess. 2010;14(6):i-v.

18. Farndon LJ, Vernon W, Walters SJ, Dixon S, Bradburn M, Concannon M, et al. The effectiveness of salicylic acid plasters compared with 'usual' scalpel debridement of corns: a randomised controlled trial. J Foot Ankle Res. 2013; 6(1):40.

19. Mountain GA, Hind D, Gossage-Worrall R, Walters SJ, Duncan R, Newbould $L$, et al. 'Putting Life in Years' (PLINY) telephone friendship groups research study: pilot randomised controlled trial. Trials. 2014;15(1):141.

20. Goodacre S, Cohen J, Bradburn M, Stevens J, Gray A, Benger J, et al. The $3 \mathrm{Mg}$ trial: a randomised controlled trial of intravenous or nebulised magnesium sulphate versus placebo in adults with acute severe asthma. Health Technol Assess. 2014;18(22):1-168.

21. Thomas SA, Coates E, das Nair R, Lincoln NB, Cooper C, Palmer R, et al Behavioural Activation Therapy for Depression after Stroke (BEADS): a study protocol for a feasibility randomised controlled pilot trial of a psychological intervention for post-stroke depression. Pilot Feasibility Stud. 2016;2(1):45.
22. McDermott CJ, Bradburn MJ, Maguire C, Cooper CL, Baird WO, Baxter SK, et al. DiPALS: Diaphragm Pacing in patients with Amyotrophic Lateral Sclerosis - a randomised controlled trial. Health Technol Assess (Rockv). 2016;20(45):1-186.

23. Mountain G, Windle G, Hind D, Walters S, Keertharuth A, Chatters R, et al. A preventative lifestyle intervention for older adults (lifestyle matters): a randomised controlled trial. Age Ageing. 2017;46(4):627-34

24. Jha S, Walters SJ, Bortolami O, Dixon S, Alshreef A. Impact of pelvic floor muscle training on sexual function of women with urinary incontinence and a comparison of electrical stimulation versus standard treatment (IPSU trial): a randomised controlled trial. Physiother. 2018;104(1):91-7.

25. Reddington M, Walters SJ, Cohen J, Baxter SK, Cole A. Does early intervention improve outcomes in the physiotherapy management of lumbar radicular syndrome? Results of the POLAR pilot randomised controlled trial. BMJ Open. 2018;8(7):e021631.

26. Cox M, O'Connor C, Biggs K, Hind D, Bortolami O, Franklin M, et al. The feasibility of early pulmonary rehabilitation and activity after COPD exacerbations: external pilot randomised controlled trial, qualitative case study and exploratory economic evaluation. Health Technol Assess . 2018;22(11):1-204.

27. Holt RI, Hind D, Gossage-Worrall R, Bradburn MJ, Saxon D, McCrone P, et al. Structured lifestyle education to support weight loss for people with schizophrenia, schizoaffective disorder and first episode psychosis: the STEPWISE RCT. Health Technol Assess. 2018;22(65):1-160.

28. Broadbent E, Petrie KJ, Main J, Weinman J. The Brief Illness Perception Questionnaire. J Psychosom Res. 2006;60(6):631-7.

29. British Spine Registry. British Spine Registry VAS (Back and Leg) Score Forms [Internet]. https://www.britishspineregistry.com/downloads/. Accessed 2 Jul 2019.

30. Collin C, Wade DT, Davies S, Horne V. The Barthel ADL Index: a reliability study. Int Disabil Stud. 1988;10(2):61-3.

31. Overall J, Gorham D. The Brief Psychiatric Rating Scale (BPRS). Psychol Rep. 1962;10:799-812.

32. Evans C, Connell J, Barkham M, Margison F, McGrath G, Mellor-Clark J, et al. Towards a standardised brief outcome measure: psychometric properties and utility of the CORE-OM. Br J Psychiatry. 2002;180:51-60.

33. Aaronson NK, Ahmedzai S, Bergman B, Bullinger M, Cull A, Duez NJ, et al. The European Organization for Research and Treatment of Cancer QLQ-C30: a quality-of-life instrument for use in international clinical trials in oncology. J Natl Cancer Inst. 1993;85(5):365-76.

34. Cox JL, Holden JM, Sagovsky R. Detection of postnatal depression. Development of the 10-item Edinburgh Postnatal Depression Scale. Br J Psychiatry. 1987;150:782-6.

35. Dolan P. Modeling valuations for EuroQol health states. Med Care. 1997; 35(11):1095-108.

36. EuroQol Group. EuroQol-a new facility for the measurement of healthrelated quality of life. Health Policy. 1990;16(3):199-208.

37. Schwarzer R, Jerusalem M. Generalized Self-Efficacy Scale. In: Weinman J, Wright S, Johnston M, editors. Measures in health psychology: a user's portfolio. Windsor: NFER-NELSON; 1995. p. 35-7.

38. Smets EM, Garssen B, Bonke B, De Haes JC. The Multidimensional Fatique Inventory (MFI) psychometric qualities of an instrument to assess fatigue. J Psychosom Res. 1995:39(3):315-25.

39. Fairbank JC, Pynsent PB. The Oswestry Disability Index. Spine (Phila Pa 1976) 2000:25(22):2940-52 discussion 2952.

40. Tinkler L, Hicks S. Measuring subjective well-being. London: Office for National Statistics; 2011. p. 29.

41. Kroenke K, Spitzer RL, Williams JBW. The PHQ-9. J Gen Intern Med. 2001; 16(9):606-13.

42. Rogers RG, Kammerer-Doak D, Villarreal A, Coates K, Qualls C. A new instrument to measure sexual function in women with urinary incontinence or pelvic organ prolapse. Am J Obstet Gynecol. 2001;184(4):552-8.

43. Ware JE, Snow KK, Kosinski M, Gandek B. SF-36 Health Survey Manual and Intepretation Guide. Boston: The Health Institute, New England Medical Center; 1993.

44. Ware JE, Kosinski M, Keller SD. SF-36 Physical and Mental Health Summary Scales: a user's manual. Boston: The Health Institute, New England Medical Center; 1994.

45. Brazier J, Roberts J, Deverill M. The estimation of a preference-based measure of health from the SF-36. J Health Econ. 2002:21(2):271-92.

46. Flemons WW, Reimer MA. Development of a disease-specific health-related quality of life questionnaire for sleep apnea. Am J Respir Crit Care Med. 1998;158(2):494-503. 
47. Roach KE, Budiman-Mak E, Songsiridej N, Lertratanakul Y. Development of a shoulder pain and disability index. Arthritis Care Res. 1991;4(4):143-9.

48. Hawker GA, Mian S, Kendzerska T, French M. Measures of adult pain: Visual Analog Scale for Pain (VAS Pain), Numeric Rating Scale for Pain (NRS Pain), McGill Pain Questionnaire (MPQ), Short-Form McGill Pain Questionnaire (SFMPQ), Chronic Pain Grade Scale (CPGS), Short Form-36 Bodily Pain Scale (SF). Arthritis Care Res (Hoboken). 2011;63(S11):S240-52.

49. Bellamy N, Buchanan WW, Goldsmith CH, Campbell J, Stitt LW. Validation study of WOMAC: a health status instrument for measuring clinically important patient relevant outcomes to antirheumatic drug therapy in patients with osteoarthritis of the hip or knee. J Rheumatol. 1988;15(12): 1833-40.

50. Walters SJ, Dos Anjos Henriques-Cadby IB, Bortolami O, Flight L, Hind D, Jacques RM, et al. Recruitment and retention of participants in randomised controlled trials: a review of trials funded and published by the United Kingdom Health Technology Assessment Programme. BMJ Open. 2017;7(3): e015276.

51. Clifton L, Clifton DA. The correlation between baseline score and postintervention score, and its implications for statistical analysis. Trials. 2019; 20(1):43.

52. Clifton L, Birks J, Clifton DA. Comparing different ways of calculating sample size for two independent means: a worked example. Contemp Clin Trials Commun. 2019;13:100309.

53. Heeren T, D'Agostino R. Robustness of the two independent samples t-test when applied to ordinal scaled data. Stat Med. 1987;6(1):79-90.

54. Sullivan LM, D'Agostino RB. Robustness and power of analysis of covariance applied to ordinal scaled data as arising in randomized controlled trials. Stat Med. 2003;22(8):1317-34.

55. Walters SJ. Consultants' forum: should post hoc sample size calculations be done? Pharm Stat. 2009;8(2):163-9.

56. Walters SJ, Campbell MJ. The use of bootstrap methods for estimating sample size and analysing health-related quality of life outcomes. Stat Med. 2005;24(7):1075-102

\section{Publisher's Note}

Springer Nature remains neutral with regard to jurisdictional claims in published maps and institutional affiliations.

Ready to submit your research? Choose BMC and benefit from:

- fast, convenient online submission

- thorough peer review by experienced researchers in your field

- rapid publication on acceptance

- support for research data, including large and complex data types

- gold Open Access which fosters wider collaboration and increased citations

- maximum visibility for your research: over $100 \mathrm{M}$ website views per year

At $\mathrm{BMC}$, research is always in progress.

Learn more biomedcentral.com/submissions 